\title{
INTERthesis
}

\section{INFLUÊNCIA DAS NORMAS INTERNACIONAIS NA PRODUÇÃO LEITEIRA BRASILEIRA: UM OLHAR CRÍTICO SOBRE AS BOAS PRÁTICAS DE PRODUÇÃO PARA A AGRICULTURA FAMILIAR NA AMAZÔNIA}

Cristiane Fonseca Costa Corrêa ${ }^{1}$

Lívia de Freitas Navegantes Alves ${ }^{2}$

\section{Resumo}

As mudanças estruturais impostas à pecuária leiteira brasileira são influenciadas pelo mercado internacional que pressiona as indústrias e, em decorrência, os produtores. Uma das principais dificuldades do setor lácteo é a padronização do leite com base nos níveis internacionais de qualidade. Para atender a essas exigências, são estabelecidos padrões operacionais de procedimento para toda a cadeia produtiva, chamados de "Boas práticas de produção leiteira". O presente ensaio aborda de forma sistêmica as influências dessas normas para a produção leiteira brasileira, e as dificuldades de adoção dos padrões de procedimento pela agricultura familiar, especialmente na Amazônia. O agricultor familiar amazônico é caracterizado por uma diversidade peculiar, relativa aos modos de produzir e viver em sociedade. Além disso, existe, ao mesmo tempo, uma diferenciação de contextos locais, muito marcantes na Amazônia, que envolvem e influenciam as práticas desses agricultores, dificultando a adesão ao princípio homogeneizante das boas práticas. A crítica deste ensaio não se reporta a necessidade de melhorias sanitárias nas práticas de produção leiteira, mas tem como linha mestra demonstrar que é necessário compreender o contexto local e a lógica dos produtores, a fim de que sejam elaboradas ações que valorizem suas práticas e que as tenham como ponto de partida. Mostra-se nesse estudo que o resultado das imposições de procedimentos para os agricultores familiares é a diferenciação e o reagrupamento social entre eles, onde uns se consolidam na produção leiteira e outros são excluídos.

Palavras-chave: Industrialização. Leite. Unidade familiar. Normativo. Diversidade.

\section{INTRODUÇÃO}

As mudanças estruturais da pecuária leiteira brasileira sofrem grande influência do mercado internacional, ocorridas a partir da abertura do mercado brasileiro para o comércio internacional diante, principalmente, das perspectivas de

\footnotetext{
${ }^{1}$ Mestranda em Agriculturas Amazônicas e Desenvolvimento Sustentável na Universidade Federal do Pará. Atua na Empresa de Assistência Técnica e Extensão Rural do Estado do Pará - EMATER/PA em Marituba, PA E-mail: cris 3030@hotmail.com

2 Doutora em Systèmes Intégrés en Biologie, Agronomie et Environnement pelo Centre International d'Etudes Supérieurs en Sciences Agronomiques, Montpellier, França. Pesquisadora Associada da rede Strategic Monitoring of South-American Regional Transformation. Professora da Universidade Federal do Pará no Núcleo de Ciências Agrárias e Desenvolvimento Rural e Mestrado em Agricultura Familiar e Desenvolvimento Sustentável em Marabá, PA. E-mail: Inavegantes@ufpa.br
} 
exportação. Em âmbito mundial a produção de leite têm sido crescente e no que tange a participação do Brasil, vem acompanhando essa dinâmica produtiva e comercial, ampliando sua participação no comércio mundial de leite desde 2004, quando as exportações tornaram-se crescentes (SANTINI, PEDRA \& PIGATTO, 2009).

Em 2014, a partir de dados da USDA (United States Departament of Agriculture), a produção brasileira de leite foi de 35,2 bilhões de litros, um aumento de 2,7\% sobre o ano anterior. Assim, o Brasil ocupou a quinta posição no ranking mundial de produção de leite, atrás de União Europeia, Índia, Estados Unidos e China (IBGE, 2014). Porém, há incertezas quanto às exportações dos produtos lácteos devido aos altos custos da produção que tornam o produto menos competitivo no mercado mundial. Entretanto, o consumo interno que chega a cerca de 177 Its per capita/ano, tem mantido o aumento da produção com preços mais rentáveis (IBGE, 2014).

Atualmente, uma das principais dificuldades do setor leiteiro brasileiro é a padronização do leite com base nos níveis internacionais de qualidade relativas às barreiras sanitárias exigidas por países importadores. Exigências que vão desde o controle do ambiente, a sanidade do rebanho,assim como cuidados específicos na ordenha, armazenamento, estocagem, transporte e manuseio do leite, além da qualidade (MILINSKI, GUEDINE \& VENTURA, 2008).

A produtividade e qualidade são imperativas no setor agrícola brasileiro e possuem forte relação com as políticas normativas e de financiamento (GEHLEN, 2001). Porém, a produção leiteira da qual tratamos neste estudo é baseada em uma categoria social que geralmente não se encaixa nessa lógica produtiva - a agricultura familiar. Para o qual, atender as necessidades da família, que é ao mesmo tempo unidade de produção e consumo, é um aspecto preponderante (CHAYANOV, 1987). Contudo, esse tipo de agricultor representa uma importante diversidade (Wanderley, 2003), de produção, o que dificulta sua adesão a um princípio homogeneizante. Outra incongruência da imposição da produtividade na agricultura, é que ela gera um censo de competitividade que não é natural dos agricultores familiares, menos familiarizados com as relações de mercado e mais adeptos da ajuda mútua, tendo como base fortes relações de parentesco e vizinhança.

R. Inter. Interdisc. INTERthesis, Florianópolis, v.13, n.1, p. 52-74 Jan-Abr. 2016 
Além da competitividade gerada pela produtividade, há outros pontos determinantes potenciais na conjuntura econômica e sócio política da gestão da atividade leiteira e que geram muitas incertezas para este setor conforme menciona Filho et al (2011), que são barreiras econômicas, entre elas a concentração agroindustrial, as políticas agrícola e agrária, o mercado globalizado, e as mudanças de comportamento e demanda dos consumidores. $E$ ainda, as barreiras não econômicas, que são socioambientais ou técnicas com a relação à exigência de qualidade na origem dos alimentos, as exigências em padrões de bem-estar animal, o comprometimento da biodiversidade e, as novas tecnologias de produção.

Dentro do exposto é importante destacar que o Banco Mundial, em informe de 2007, destacou o papel fundamental da agricultura para a redução da pobreza no meio rural até 2015, cujo documento continha orientações de como colocar em prática programas de desenvolvimento para a agricultura que resultem em melhorias para milhões de pessoas de baixa renda que vivem no meio rural, incluindo a agricultura familiar (FAUTT, 2008).

No que diz respeito a estes programas de desenvolvimento, na tentativa de se alinhar às transformações econômicas e às exigências do setor agrícola, são estabelecidos procedimentos padrões, chamados de "Boas práticas".

Segundo Farah (2008), o conceito de 'boas práticas' aplica-se a diversos campos disciplinares e refere-se principalmente a processos gerenciais destacados em pontos comuns nas áreas que se aplicam: foco no desempenho, foco na técnica e a ideia de modelo a ser replicado. Apresentando-se como solução completa e integral, fechada, específica e única, capaz de responder a um desafio ou problema. Este olhar implica em desconsiderar a importância e particularidade de diferentes contextos locais, comprometendo o processo de transformação almejado.

A imposição destes modelos tende a atribuir ao adotante uma incapacidade de interferir, uma passividade que o desqualifica como ator, como participante ativo de processos decisórios e de processos políticos (FARAH, 2008). Países como o Brasil priorizam a adoção de conhecimentos e tecnologias de países desenvolvidos que vêm em formato de pacotes tecnológicos, geralmente implantados forçadamente sem considerar as tradições culturais e formas de organização e produção locais (GEHLEN, 2001).

R. Inter. Interdisc. INTERthesis, Florianópolis, v.13, n.1, p. 52-74 Jan-Abr. 2016 
As "Boas práticas" atualmente abrangem não somente o campo da administração, mas se expandiu por diversas áreas envolvidas na gestão de qualidade. Da mesma forma, não se aplica somente a pecuária leiteira, mas a diversos setores da agropecuária, como a produção apícola, a agricultura e a pecuária de corte, que conjuntamente são chamadas "Boas práticas agropecuárias. Essas normas de procedimento são formuladas e indicadas por diferentes instituições, mesmo dentro de um mesmo setor agrícola, tendo-se, por exemplo, as "Boas Práticas" de produção leiteira", dentre as quais temos as boas práticas aplicadas à agroindústria, aos produtores de leite, aos laticínios e ainda por sindicatos ou associações produtoras de leite.

Essas normas processuais podem ser estabelecidas desde o nível internacional até o regional (como é o caso daquelas estabelecidas por alguns laticínios). Contudo, o nível internacional é que molda as "Boas práticas" nacionais e regionais.

Neste ensaio refletiremos sobre o modelo de produção leiteira estabelecida pela $\mathrm{FAO}$, a nível internacional e sua influência de forma descendente na pecuária leiteira no Brasil. Analisaremos os procedimentos que surgiram em respostas a busca pela qualidade e segurança e numa abordagem sistêmica o reflexo sobre a produção leiteira da agricultura familiar amazônica.

\section{UM OLHAR SOBRE AS BOAS PRÁTICAS AGROPECUÁRIAS}

A expansão do comércio internacional tem induzido ao aumento das exigências quanto à qualidade dos produtos. A qualidade dos alimentos pode envolver diversas características, como o aspecto visual, o sabor, e a associação com a cultura e o local de origem, Porém, muitas vezes a qualidade é relacionada a aspectos sanitários, e mais amplamente a saúde do consumidor, podendo ser associada, ou não, a outros aspectos.

Contudo, é necessário reconhecer que o termo qualidade é bastante controverso. Segundo Harvey, McMeekin e Warde (2004), esse termo envolve o empírico e o normativo: ele estabelece um julgamento, que pode ser objetivo ou subjetivo, e se refere a condições preestabelecidas. Nesse estudo, nos referimos a 
qualidade quanto a seu aspecto sanitário, em virtude de se ter um determinado consenso quanto a importância desse critério com relação aos produtos lácteos.

A preocupação pela qualidade dos alimentos tem aumentado as exigências para os produtores. Esse processo iniciou nos países desenvolvidos, que dispõem de infraestrutura e acesso às tecnologias, com consumidores cada vez mais exigentes, que exercem grande influência na elaboração das normas e leis e na atuação das autoridades competentes. Nesse contexto, estes países vêm restringindo a entrada de alimentos importados que não atendam os requisitos de qualidade, saúde e preservação do meio ambiente, criando barreiras técnicas de caráter protecionista (ROUGEMONT, 2007).

Conforme a FAO (2013), as boas práticas agropecuárias (BPA) aplicadas à pecuária leiteira são procedimentos adequados em todas as etapas da produção de leite nas propriedades rurais. Entretanto, deve-se questionar o que é considerado adequado e em que ponto de vista, e ainda, como é visto o contexto local das propriedades produtoras de leite.

A influência da regulamentação mundial é exercida a partir do Codex Alimentarium e da Food and Agricultural Organization (FAO), os quais são órgãos que definem e recomendam a adoção das Boas práticas de fabricação e produção em todas as cadeias produtivas, entre elas a produção de leite (ROUGEMONT, 2007). Esta regulamentação técnica que indica a garantia de segurança e características do leite e produtos lácteos está contida no Codex Recommended International Code of Practice - General Principles of Food Hygiene (Código Internacional de Práticas Recomendadas pelo Codex - Princípios Gerais de Higiene dos Alimentos), juntamente com o Codex of Hygienic Practice for Milk and Milk Products (Código de Práticas de Higiene para o Leite e os Produtos Lácteos) (FAO, 2013).

Na diversidade de culturas e modos de vida em sociedade que vão desde o rural até a cidade, um código padrão de práticas como este, gera uma imposição sobre a forma de produzir destes produtores, se não forem observados os contextos locais antes de serem aplicadas. O resultado dessas imposições é a diferenciação e reagrupamento social entre os agricultores, onde uns são consolidados e outros excluídos (GELHEN, 2001).

R. Inter. Interdisc. INTERthesis, Florianópolis, v.13, n.1, p. 52-74 Jan-Abr. 2016 
A FAO alega que os produtores de leite são parte integrante de uma ampla cadeia alimentar e de processamento e que todos os elos (produtores de leite, fornecedores de insumos, transportadores, indústrias, processadores de leite e de alimentos, distribuidores, varejistas e consumidores) devem estar integrados a fim de garantir a segurança e qualidade dos produtos. Nesse sentido, para que os produtores se adequem aos padrões internacionais de qualidade e segurança, devem aplicar as boas práticas em suas propriedades nas seguintes áreas: saúde animal, higiene na ordenha, nutrição (alimento e água), bem-estar, meio-ambiente e gestão socioeconômica (FAO, 2013).

Apesar da relevância e importância da produção de alimentos seguros e de qualidade, deve-se levar em conta que o rural possui diversidades específicas em todo o mundo, assim como os produtores nele inseridos. Concordando com Carneiro (1998) que diz que de modo algum os efeitos das medidas modernizadoras sobre a população do campo produz reações uniformes ou em vistas disso considerar que são homogêneas, pois elas expressam formas diferentes em universos culturais, sociais e econômicos heterogêneos.

A crescente exigência internacional por produtos seguros, conduziu as autoridades brasileiras a seguirem a tendência de elaboração de leis e normas que disciplinem a produção de alimentos, o que consideramos um avanço para a saúde pública, e a partir de 1993, as primeiras portarias legais são introduzidas pelo Ministério da saúde e pelo Ministério da Agricultura com relação às Boas práticas de fabricação (BPF), entre as quais temos: a BPF de alimentos e de produtos agropecuários.

Contudo, esses padrões normativos são traduções daqueles adotados em mercados mais desenvolvidos e que se tornaram, pelo pioneirismo, referências para aqueles que se seguiram (ROUGERMONT, 2007). Dessa forma, considerando o que diz Santos (2011), a imitação, por parte dos países do terceiro mundo, em seguir o modelo implementado pelos países desenvolvidos é uma questão de necessidade mais do que de escolha.

As empresas são pressionados pela abertura do mercado internacional a se adequarem aos padrões de competitividade (produtividade e qualidade) segundo determinantes do mercado globalizado, o que impõe riscos a existência das empresas caso elas não se adequem a estas exigências (GEHLEN, 2001; FILHO et 
al (2011)). Assim também, os produtores, principalmente os pequenos, que estão ligados ao setor leiteiro correm os mesmos riscos de serem alijados da atividade.

Considerando o que Rougemont (2007) diz, a segurança dos alimentos deixou de ser uma preocupação tão somente de saúde pública e tornou-se uma barreira comercial para exportações. No setor agropecuário, as indústrias de processamento de matéria-prima fazem a intermediação entre as exigências internacionais e os produtores agrícolas. O Estado apóia esse processo diante dos interesses em gerar desenvolvimento econômico e manter um controle sobre toda a cadeia produtiva.

A legislação brasileira exige que estabelecimentos que manipulem, produzem ou industrializem alimentos implantem as Boas práticas de fabricação, que são um conjunto de procedimentos relacionados às instalações de produção, equipamentos, conservação de áreas internas e externas, controle de pragas, uniformes e capacitação de funcionários para que sejam cumpridas as condições necessárias à produção de alimentos. Assim, é exercido um controle da cadeia de suprimentos que vai desde o campo até a mesa do consumidor (ROUGERMONT, 2007).

Em 2002 foi realizada uma revisão da legislação sobre as normas e padrões de qualidade para a produção e comercialização do leite, pois esta legislação era bem antiga, de 1952, a qual foi reformulada e transformada em uma política pública federal mais abrangente e estratégica para o setor lácteo brasileiro. Nasce então, o Programa Nacional da Melhoria da Qualidade do Leite - PNMQL, que em vigor desde 2005 uniformizou os padrões de produção e controle do leite para as grandes e pequenas propriedades (MILINSKI, GUEDINE \& VENTURA, 2008). Dessa forma, o governo brasileiro desconsidera as diferenças estruturais e funcionais entre estabelecimentos rurais de diferentes portes. Assim, em um ambiente de competição, essa ação do estado resulta no favorecimento de grandes propriedades, mais aptas a aderirem às normas de origem internacional.

Nesse contexto, a questão da pecuária leiteira brasileira é um caso ilustrativo de mudanças tecnológicas com impactos sociais, devido à produção brasileira ser vista como de baixa produtividade, percebemos a tentativa de se adequar ao mercado internacional adotando procedimentos bem distantes da realidade nacional. Dando a entender que a permanência de produtores considerados de baixa produtividade e em muitos casos, do tipo tradicional seja um risco para o avanço da 
atividade leiteira e que se constitui um desafio, pois apesar de representar, uma potencialidade de expansão da produção e sustentabilidade pela preservação de base social, por outro lado, representa um potencial de exclusão pelo processo de seleção imposto por essas mudanças (GEHLEN, 2001).

\section{AS BOAS PRÁTICAS PARA A AGRICULTURA FAMILIAR}

A agricultura familiar é uma categoria social bem específica e que Lamarche (1993), expressa como sendo portadora de uma tradição que se caracteriza pela centralidade na família, pela forma de produzir e pelo modo de vida, que são traços oriundos do camponês, os quais tem que adaptar-se às condições de produzir e viver na sociedade a qual de certa forma os engloba e os torna inseridos no mercado. Da mesma forma, Wanderley (2003) ressalta que mesmo sendo moderno e inserido no mercado, esse agricultor preserva seus traços camponeses, tendo ainda que enfrentar problemas específicos relacionados à modernização brasileira, dependendo em muitos casos de seus próprios esforços.

Diante dessas características da agricultura familiar, suas relações com as indústrias costumam ser rodeadas de tensões, diante de lógicas e princípios distintos. Por um lado, as indústrias valorizam a produção de larga escala e a maximização dos lucros. Mas a agricultura familiar fundamenta sua produção na tradição e na família tendo a autonomia como elemento chave de suas relações sociais (ALMEIDA, 1999).

Não podemos deixar de destacar que o mundo rural participa de um universo socialmente integrado ao conjunto da sociedade brasileira e aos contextos atuais de relações internacionais, não é um universo isolado nem autônomo nem exclusivo com relação a sociedade. Ao contrário, possui peculiaridades históricas, sociais, culturais e ecológicas que o identificam com uma realidade própria, e que dão origem as suas próprias formas de inserção nesta sociedade que os engloba (WANDERLEY, 2002)

A agroindustrialização pelos próprios agricultores familiares vem sendo imposta pelo governo federal, como forma de agregação de valor e geração de renda. Assim, em 2003 é lançado o Programa nacional de agroindustrialização da agricultura familiar pelo ministério do desenvolvimento agrário (MDA). Esse 
programa tem como principais linhas de ação: o crédito e capacitação de agricultores e técnicos em diversos aspectos ligados a produção de matéria prima, beneficiamento e comercialização (BRITO, PINTO \& BRITO, 2006). Porém, essa política não questiona e nem se propõe a fazer avançar a legislação para que ela esteja mais adequada à realidade da agricultura familiar, ao contrário, uma das linhas de ação é justamente de "Adequação e Orientações nas Legislações Específicas".

Em 2006, é lançado o guia de Recomendações Básicas para a Aplicação das Boas Práticas Agropecuárias e de Fabricação na Agricultura Familiar, com a finalidade de orientar os agricultores familiares a cumprir as exigências de adequação por parte do mercado nacional e internacional. Ressaltando, o código de defesa do consumidor com relação ao fornecimento de produtos que não acarretem riscos a saúde ou a segurança dos consumidores, regulamentações do Ministério da Saúde e Ministério da Agricultura quanto à produção de alimentos seguros. Destacando os princípios das boas práticas agropecuárias e de fabricação, formas de rotulagem, produção de vegetais, animais, entre outros temas referidos a cadeia de produção e agroindustrialização familiar, inclusive as Boas práticas de produção de leite bovino na agricultura familiar (BRITO, PINTO \& BRITO, 2006)

Assim como a indústria de alimentos atualmente é obrigada a aplicar procedimentos de controle para evitar a contaminação no ambiente do processamento (FILHO et al, 2011), entende-se que seja necessário que a matériaprima entregue pelos produtores rurais também atenda a princípios semelhantes, garantindo a sustentabilidade do setor diante das exigências para exportação de alimentos e dos consumidores dentro do País (BRITO, PINTO \& BRITO, 2006). Entretanto, estes princípios não consideram as diversidades regionais e as desigualdades existentes entre as agriculturas (agricultura familiar e agricultura patronal) (FILHO et al, 2011), além da diversidade existente entre os próprios agricultores familiares.

As boas práticas aplicadas à produção de leite na agricultura familiar envolvem como pontos principais a produção higiênica do leite (currais, sala de ordenha, qualidade da água, saúde do rebanho e bem estar animal); práticas gerais de manejo e higiene (alimentação, controle de pragas, emprego de medicamentos veterinários); manejo de ordenha; pós-ordenha: armazenamento e transporte do leite 
(utensílios utilizados na coleta do leite cru, transporte); saúde e treinamento do pessoal envolvido na ordenha e manipulação do leite; e meio ambiente (BRITO, PINTO \& BRITO, 2006), tendo sido formulada a partir de procedimentos préconcebidos e experimentados em unidades produtivas distintas das unidades de produção familiar.

Contudo, é importante levar-se em conta os contextos locais e sua diversidade no Brasil, quando se pretende a aplicação destes procedimentos que, de forma padronizada e modelada segundo o estilo de gestão empresarial, são impostas à agricultura familiar, os expondo a um processo seletivo de exclusão. Santos (2011) ressalta que o retorno à realidade consiste em considerar estas realidades particulares a cada país ou lugar, partindo da aplicação de modelos para os quais a prática humana de novo torna-se o guia essencial possibilitando um diálogo entre as formulações teóricas e o empírico, de suma que as realidades em mudanças imporão reajustes aos princípios teóricos ou até mesmo poderão substituí-los.

Podemos considerar como um grande passo nessa direção, a implementação pelo MAPA (Ministério da Agricultura, Pecuária e Abastecimento) da Instrução normativa 16 (IN 16), em julho de 2015, a partir da pressão exercida pelos movimentos sociais dos agricultores familiares, sendo um grande diferencial visto que anteriormente a ocorrência dava-se por pressão de países importadores.

Entre os avanços desta normativa destaca-se a flexibilidade com relação às instalações e procedimentos e até mesmo a isenção de pagamento de taxas de registro e de inspeção e fiscalização sanitária, além da dispensa de despesas com o serviço de inspeção (condução, deslocamento, alimentação, instalações, equipamentos, etc), o responsável técnico poderá ser suprido por técnico de órgãos governamentais, exceto agente de fiscalização sanitária, e ainda o respeito à especificidade da agroindústria de pequeno porte quanto a identidade e qualidade dos produtos de origem animal (MAPA, 2015).

Entretanto, apesar dos avanços que após regulamentados pelas agências de defesa estaduais trarão grandes benefícios a este público, a IN 16, ainda restringe os produtos da agricultura familiar a mercados locais, impedindo seu acesso a outros mercados, inclusive dentro do mesmo estado. 


\section{O CONTEXTO AMAZÔNICO}

Na Amazônia, segundo Théry (2000), pode-se distinguir duas grandes dinâmicas de ocupação do espaço: 1) A Amazônia dos rios: ocupada por populações tradicionais, instaladas há séculos à margem dos rios, e que praticam o extrativismo e/ou uma agricultura de corte e queima; 2) A Amazônia das estradas: marcada pelo avanço das fronteiras agrícolas, onde a pecuária ocupa um espaço importante.

Desde o período colonial a região amazônica integrou-se ao mercado mundial como frente de exploração mercantil, com destaque para a pecuária, particularmente a bubalina, nas áreas de campos naturais da llha do Marajó. Até a década de 1960, a pecuária era praticada apenas nestes campos naturais, onde data do século XII. Entre 1960 e 1970, a Amazônia passou por um intenso processo de desenvolvimento e de transformação em suas bases produtivas, sendo que a região do Marajó ficou fora desse processo, com a implantação de outro sistema pecuário com base em latifúndio, com pastagem cultivada em áreas desmatadas (BARBOSA, 2012).

Vamos nos focalizar no contexto das estradas, por ser o espaço onde se pratica a pecuária leiteira, mesmo que rios e estradas se cruzem constantemente e exerçam influência mútua.

A expansão da pecuária na Amazônia ocorreu especialmente a partir da década de 1970, principalmente diante da política de incentivos fiscais a grandes projetos agropecuários, em uma estratégia do governo militar de ampla colonização da região (HÉBETTE, 2004). Esse processo de expansão da pecuária foi facilitado e acelerado pela abertura de grandes rodovias na região (HOSTIOU, VEIGA \& TOURRAND, 2006).

Assim sendo, podemos considerar que a pecuária bovina na Amazônia é uma atividade relativamente recente e se insere em um contexto de expansão da fronteira agrícola e, portanto, de pouca infraestrutura. Segundo Navegantes-Alves (2012), essa ainda é uma das regiões com pior infraestrutura do país, tendo-se muitos estabelecimentos sem eletricidade, com estradas precárias e habitações dispersas, sem estruturas urbanas.

R. Inter. Interdisc. INTERthesis, Florianópolis, v.13, n.1, p. 52-74 Jan-Abr. 2016 


\section{OS SISTEMAS DE PRODUÇÃO FAMILIARES}

Segundo Hostiou, Veiga e Tourrand (2006) a relevância da pecuária leiteira nos sistemas produtivos familiares da Amazônia ocorre a partir de 1990, contribuindo para a sustentabilidade da agricultura familiar. Sendo de suma importância para a mesma, tanto na renda mensal quanto na questão da segurança alimentar, demonstrando em diversas regiões da Amazônia a dinâmica de expansão da atividade como um potencial de viabilidade econômica para a agricultura familiar (CARVALHO, TOURRAND \& POCCARD-CHAPUIS, 2012).

A agricultura familiar da Amazônia possui uma característica marcante que é a diversidade de atividades, o que a diferencia de outras regiões do país, predominantemente especializadas, como é o caso de Minas gerais. Esta diversidade consiste em variedades de cultivos vegetais, sistemas de criação de pequenos e médios animais, criação de bovinos, havendo uma forte interação entre os mesmos, tornando-os menos vulneráveis do que sistemas especializados de produção (CARVALHO, TOURRAND \& POCCARD-CHAPUIS, 2012). Esta característica no ponto de vista da pecuária de leite especializada é considerada como um entrave para a produtividade de qualidade na agricultura familiar.

Contudo Mesquita (2008) ressalta que a passagem de uma agricultura 'tradicional' para outra 'moderna', nos moldes que foi realizado no campo brasileiro, com redução de força de trabalho, sempre virá acompanhada de redução de emprego e destruição ambiental, o qual considera ainda que o capital no campo não trouxe o que se esperava em termos de aumento de renda ou produção de alimentos básicos, muito menos uma modernização que contemplasse de forma justa e generalizada todos os atores envolvidos.

É notório que o processo econômico, a globalização e estruturas que viabilizam o agronegócio, interferem consideravelmente na estabilidade da agricultura familiar. O contexto histórico em relação ao processo de ocupação e colonização e a evolução das formas familiares, assim como sua configuração atual, são os principais elementos que podem explicar as determinadas práticas dos produtores familiares (RIBEIRO, BRANT \& PINHEIRO, 2009).

Hostiou, Veiga e Tourrand (2006) ressalta ainda que a diversidade das propriedades leiteira na Amazônia vai desde o nível da estrutura de produção a 
evolução da mesma e confirma dessa forma, a necessidade de formular medidas diferenciadas e adaptadas às realidades locais.

Para evidenciar estas diversidades entre as propriedades e trazendo para o cumprimento ou não da normativa de Boas práticas, exemplifico a seguinte situação com base nos dados de pesquisa ${ }^{3}$ realizada no período de março a maio de 2014 , no município de Paragominas, região do nordeste paraense, fronteira de colonização agrícola no Pará, destacando as boas práticas relacionadas aos critérios: transporte e armazenamento, água e meio ambiente conforme quadro 1. Este estudo foi realizado com 60 agricultores familiares produtores de leite, onde identificou-se que $30 \%$, participaram de alguma capacitação na atividade leiteira e os demais detinham algum conhecimento de cuidados na ordenha e produção de leite adquiridos com a prática diária ou participação em palestras.

Quadro 1 - Aplicação das Boas práticas considerando as dificuldades com relação à localização.

\begin{tabular}{|lccc|}
\hline $\begin{array}{l}\text { Boas práticas de produção } \\
\text { para a agricultura familiar } \\
\text { (MDA, 2006). }\end{array}$ & Colônia do Uraim ${ }^{1}$ & $\begin{array}{c}\text { Colônia Nova } \\
\text { Vida }\end{array}$ & $\begin{array}{c}\text { Assentamento } \\
\text { Luís Inácio - } \\
\text { Nova Jerusalém }\end{array}$ \\
\hline $\begin{array}{l}\text { Transporte até a indústria ou } \\
\text { tanque de resfriamento } \\
\text { dentro do prazo previsto }\end{array}$ & Sim & Não & Não \\
\hline $\begin{array}{l}\text { Refrigeração imediatamente } \\
\text { após a ordenha (até 2 h após } \\
\text { a ordenha*) }\end{array}$ & Sim & Não & Não \\
\hline $\begin{array}{l}\text { Possui água próximo à área } \\
\text { de ordenha }\end{array}$ & Sim & Não & Não \\
\hline $\begin{array}{l}\text { Disponibiliza água limpa à } \\
\text { vontade para os animais }\end{array}$ & Sim & Não & Não \\
\hline $\begin{array}{l}\text { Mantém área de reserva } \\
\text { ambiental }\end{array}$ & Não & Sim & Sim \\
\hline $\begin{array}{l}\text { Descarte de embalagens, } \\
\text { seringas e agulhas. }\end{array}$ & Não & Não & Não \\
\hline
\end{tabular}

Fonte: Elaborado pelos autores. ${ }^{*}$ I.N. 51, 18 de setembro de 2002/MAPA.

'Distância da sede do município 6 km; '2 distância da sede do município $75 \mathrm{~km}$; ${ }^{3}$ distância da sede do município $125 \mathrm{~km}$.

A realidade das comunidades produtoras de leite na Amazônia diverge inclusive dentro de um mesmo contexto local, como é o caso destas comunidades em destaque na tabela 1. As quais fazem parte de um mesmo município, Paragominas, que possuem produtores de leite da agricultura familiar. Contudo, analisando uma das características de suas realidades específicas que é a

${ }^{3}$ Esse estudo se insere no projeto de pesquisa ECOTERA - ECOeficiência e desenvolvimento TERritorial na Amazônia Brasileira, financiado pela ANR (Agência Nacional de Pesquisa da França).

R. Inter. Interdisc. INTERthesis, Florianópolis, v.13, n.1, p. 52-74 Jan-Abr. 2016 
localização com relação à sede do município, podemos perceber diferenças e similaridades entre elas, e dificuldade na adoção das boas práticas recomendadas, devido a fatores externos que pressionam estes produtores familiares.

A colônia do Uraim fica mais próxima da sede do município e por esta análise percebe-se que pelo menos quatro das boas práticas recomendadas são atendidas ou adotadas, devido esta proximidade. As vias de acesso são viáveis e de bom estado e estão sempre recebendo manutenção, o que favorece o transporte dos produtos produzidos, conduzindo ao surgimento de uma bacia leiteira muito promissora com a presença de laticínio de pequeno porte, entrada de tanque de resfriamento de laticínio de grande porte, promovendo a ocorrência de linhas de coleta de leite, viabilizando assim a produção das unidades familiares locais com valorização do produto e preço. Desta forma conseguindo atender as exigências de armazenamento e transporte.

Esta proximidade também favorece a disponibilidade de água nos ambientes necessários à produção de leite, assim como para os animais, pois a maioria das famílias possuem poço artesiano e o custo para estabelecer estruturas para canalizar a água às áreas exigidas não se torna oneroso, permitindo que grande parte das propriedades consigam atender este critério. Em contrapartida, a proximidade da área urbana prejudica atender a questão ambiental, pois esta foi uma área de grande incidência de madeireiras, o que comprometeu a presença de floresta, que é quase inexistente na comunidade.

As colônias Nova Vida e Nova Jerusalém possuem uma realidade idêntica apesar de estarem bem distantes uma da outra, pois quando comparamos à proximidade à sede do município elas enfrentam a mesma dificuldade para atender as boas práticas exigidas de transporte e armazenagem porque o acesso é dificultoso devido ao estado das estradas e principalmente durante o inverno quando são cortadas pela enchente dos rios da região, levando a comunidade Nova Jerusalém a ficar totalmente isolada.

Estas impossibilidades impedem que estes produtores produzam o leite cru para comercialização, por não conseguirem cumprir as exigências de transporte e armazenamento no prazo exigido. Além disso, por estar mais distante, a Comunidade Nova Jerusalém sofre ainda a instabilidade da energia que é um 
determinante para a refrigeração adequada do leite e instalação de tanque de resfriamento ou laticínio.

Contudo, produtores desta comunidade por serem tradicionais na atividade e mais experientes, se organizaram e formaram uma cooperativa e estão construindo uma queijaria artesanal para solucionar a questão, pois assim poderão se manter na atividade e comercializar seus produtos sem problemas legais.

Entretanto, a realidade dos produtores da Colônia Nova vida é distinta, pois os produtores são novos na atividade, não tem experiência na atividade leiteira nem tradição, são experientes na agricultura. Iniciaram na atividade por incentivo da assistência técnica e adquiriram os animais através de financiamento, enfrentando desta forma dificuldades mais severas, o que tem desestimulado a permanência dos mesmos na atividade. Visto que a comercialização do queijo da forma que produzem ser a única forma de não perderem a produção, ainda é considerada inadequada e clandestina.

Por estarem também mais distantes da área urbana, tanto a Colônia Nova Vida quanto a Comunidade Nova Jerusalém possuem bastante áreas de floresta, atendendo a questão ambiental. Com relação à água, dispõem de água de rio e poço comum, não disponibilizando água limpa e à vontade aos animais. Estes são criados extensivamente com pouco controle de área de pastejo.

Com relação ao descarte de embalagens, nenhuma das três comunidades atendem esta boa prática, pois não há um ponto de coleta específico e as lojas não fazem esta coleta, alegando que o centro de recebimento é distante do município. Alguns destes produtores não têm como transportar as mesmas, descartando-as no ambiente, assim como seringas e descartáveis que também não possuem coleta específica na região.

É algo muito sério e perigoso, pois mesmo enterrando estes materiais, devido à região amazônica ser uma área de intensas e prolongadas chuvas, a lixiviação pode contaminar rios e açudes, assim como o solo com resíduos desses produtos, ou até mesmo desenterrando-os na ocorrência de enchentes e erosões.

Outra similaridade entre as comunidades, identificada através das entrevistas, é a preocupação e consciência da importância das práticas de higiene do leite. Dos agricultores entrevistados, cerca de $13 \%$ já estão adaptados e 50\% estão em um caminho de adaptação às práticas de higiene na ordenha e produção do leite, por 
considerarem que assim seus produtos terão maior aceitação no mercado e o preço pago poderá ser maior. Nesse sentido, tivemos vários relatos referentes às mudanças relativas às crescentes exigências sanitárias, que demonstravam tanto as dificuldades em cumpri-las quanto à percepção de sua implicação para a saúde e da necessidade de apoio; como coloca uma das interlocutoras de nossa pesquisa:

Devido às exigências de higiene ficou mais difícil produzir o leite, mas vejo que essas cobranças são importantes para a nossa saúde, então queremos melhorar e agora temos apoio da pesquisa e da assistência técnica que nos ajudará muito (Gelci Ignês Pedrotte, Colônia Uraim, Sítio Progresso, 2014)..

Confome o exposto, segundo Hostiou, Veiga e Tourrand (2006) as propostas de intervenção devem favorecer a integração e a permanência da produção leiteira fortalecendo o funcionamento dos sistemas e melhorando a condição de produção, de forma que as políticas públicas devem ser reformuladas para apoiar o desenvolvimento da atividade, através de cooperativas e associações de produtores de leite e também políticas para absorver a produção, sendo essencial melhorar a infraestrutura das bacias leiteiras que são estradas, rede de coleta de leite, energia, etc.

As realidades dos produtores da Amazônia devem ser consideradas peculiares inclusive entre o seu próprio meio, pois o exemplo nos faz perceber que são distintas e que podem excluí-los de um processo de desenvolvimento local, o que Hostiou (2006) considera que deve haver estudos mais focados nestes sistemas de produção leiteira, a fim de procurar mais especificamente caracterizar as práticas desenvolvidas pelos produtores $\mathrm{e}$ as razões delas, contribuindo para uma compreensão melhor de suas realidades, facilitando desse modo, a difusão de recomendações, assim como a melhoria de ações de políticas públicas e desenvolvimento local.

\section{CONSIDERAÇÕES FINAIS}

Em face de todas as mudanças estruturais ocorridas na pecuária leiteira brasileira pela influência do mercado internacional, e a decorrência do surgimento de tantas exigências e procedimentos para a obtenção da matéria-prima leite, dentro de padrões internacionais de segurança e qualidade, que são as boas práticas de produção de leite, e ainda a influência de órgãos internacionais sobre as normativas e legislação brasileira, diante de uma diversidade de atores deste setor no cenário

R. Inter. Interdisc. INTERthesis, Florianópolis, v.13, n.1, p. 52-74 Jan-Abr. 2016 
nacional, faz-se importante considerar a dificuldade em se encontrar uma normativa que padronize todos os lugares produtores de leite no Brasil, de forma a preservar a permanência dos mesmos na atividade, considerando o contexto em que vivem.

Não se trata de ignorar a necessidade de produtos e alimentos de qualidade e segurança, e sim, refletir sobre um olhar além e ao redor, a fim de se perceber a diversidade dos produtores de leite, tanto em suas relações entre si, quanto com o meio que os envolve, e que a vasta extensão territorial de nosso país, permite a existência de uma heterogeneidade relevante à nível local, regional e nacional. A escala principal do problema é o meio envolvente e não propriamente 0 estabelecimento em si.

Considera-se uma certa conscientização por parte destes produtores de que os alimentos devem ser produzidos de forma higiênica, com qualidade e segurança, eles compreendem que isto é importante com base no conhecimento que alguns adquirem e replicam a outros, por serem os primeiros consumidores destes produtos e pela valorização no mercado. Contudo, a crítica diz respeito ao porque estes procedimentos desconsideram as realidades e o meio em que estes produtores estão inseridos, porque desconsideram sua forma de produzir e modo de fazer, porque alimento de qualidade e seguro somente é considerado aquele que passou por um processamento ou beneficiamento agroindustrial.

Quando trazemos para o panorama da região amazônica, esta diversidade torna-se muito mais complexa e de contextos distintos, como já mencionamos neste estudo, sendo percebida inclusive entre agricultores familiares vizinhos em uma mesma localidade, práticas e modo de vida diferenciados.

Esta percepção de complexidade e dificuldades de infraestrutura existentes na Amazônia deve ser levada em conta pelos órgãos estaduais, secretarias de agricultura, técnicos da extensão rural e gestores de indústrias do setor lácteo, cooperativas entre outros relacionados a esta área de abrangência, a fim de que sejam formuladas políticas de desenvolvimento específicas para a agricultura familiar amazônica, promovendo a produção com preservação de suas identidades.

Para se evitar a exclusão destes agricultores familiares, faz-se necessário a construção de procedimentos numa forma de produzir com qualidade e segurança através de uma perspectiva que valorize a realidade destes produtores, seu modo de vida, suas práticas e estilos próprios. Sendo necessária para isso uma 
aproximação maior de todo o contexto produtivo que os envolve, considerando que a implantação da IN 16 seja um dos passos para que isto ocorra, a fim de que se estabeleçam procedimentos peculiares que preservem suas tradições, o meio ambiente, que não lhes pressione de maneira a gerar instabilidade a permanecer na atividade, mas que os inclua no processo de desenvolvimento que ora estão inseridos.

R. Inter. Interdisc. INTERthesis, Florianópolis, v.13, n.1, p. 52-74 Jan-Abr. 2016 


\title{
INTERNATIONAL STANDARDS' INFLUENCE IN BRAZILIAN MILK PRODUCTION: A CRITICAL PERSPECTIVE ABOUT THE GOOD MANUFACTURING PRACTICES FOR FAMILY FARMS IN THE AMAZON REGION
}

\begin{abstract}
:
Structural changes imposed on Brazil's dairy industry are influenced by the international market while it presses local industries and local producers. One of the main difficulties in the dairy sector is the standardization of milk based on the international standards of quality. So, to meet these requirements, standard operating procedures are established for the entire production chain, and they're called " Good dairy farming practices". This paper addresses in a systemic way the influences of these standards in the Brazilian milk production, and the difficulties for adopting these procedure standards in family farming, especially in the Amazon region. The Amazonian family farmer is characterized by a peculiar diversity related to the ways they produce and live in society. In addition, there is at the same time a variety of local contexts very striking in the Amazon, which involve and influence the practices of farmers, making it difficult to join a homogenizing principle of good practices. The criticism of this paper does not report the need for sanitation improvements in milk production practices, but it wants to demonstrate as a leading line that the local context and the logic of producers are extremely necessary, so that the actions elaborated can value their practices and have them as a starting point. It should be noted in this study that the result of standard procedures for family farmers is the differentiation and social reunification in between them, where some are consolidated in milk production and others are excluded.
\end{abstract}

Keywords: Industrialization. Milk. Family unity. Normative. Diversity.

\section{INFLUENCIA DE LAS NORMAS INTERNACIONALES EN LA PRODUCCIÓN LECHERA BRASILERA: UNA MIRADA CRÍTICA SOBRE LAS BUENAS PRÁCTICAS DE PRODUCCIÓN PARA LA AGRICULTURA FAMILIAR DE LA AMAZONIA.}

\section{Resumen:}

Los cambios estructurales impuestos a la ganadería lechera brasilera son influenciados por el mercado internacional que presiona a las industrias y en consecuencia, a los productores. Una de las principales dificultades del sector lácteo es la estandarizacion de la leche en base a los niveles internacionales de calidad. Para atender esas exigencias, son establecidos patrones operacionales de procedimiento para toda la cadena productiva llamados "Buenas prácticas de producción lechera". El presente ensayo aborda de forma sistemica las influencias de esas normas para la producción lechera brasilera y las dificultades de adopción de los patrones de procedimiento por la agricultura familiar, especialmente en la Amazônia. El agricultor familiar amazónico es caracterizado por una diversidad peculiar, relativa a los modos de producir y de vivir en sociedad. Además de eso, existe, al mismo tiempo, una diversidad de contextos locales, muy marcantes en la Amazonia que envuelven e influencian las practicas de esos agricultores dificultando la adhesión al principio homogeneizante de las buenas prácticas. La crítica de este ensayo no se reporta a la necesidad de mejoras sanitarias en las prácticas de producción lechera, mas tiene como línea directriz demostrar que es necesario comprender el contexto local y la lógica de los productores a fin de que sean 
elaboradas acciones que valoricen sis prácticas y que las tengan como punto de partida. Este estudio destaca que el resultado de las imposiciones de procedimientos para los agricultores familiares es la diferenciación y el reagrupamiento social entre ellos, en donde unos se consolidan en la producción lechera y otros son excluidos.

Palabras clave: Industrialización. Leche. Unidad familiar. Normativo. Diversidad 


\section{REFERÊNCIAS}

ALTAFIN, I. Reflexões sobre o conceito de agricultura familiar. Enfoc. 2007.

Disponível em:

http://www.feis.unesp.br/Home/departamentos/fitotecniatecnologiadealimentosesocio economia716/antoniolazarosantana/conceito-de-agricultura-familiar.pdf. Acesso em: 14 jan. 2015.

BARBOSA, Maria José de Souza (Coord.). Relatório Analítico do Território do Marajó. Universidade Federal do Pará. Belém, PA. 2012, p. 79. Disponível em: http://sit.mda.gov.br/download/ra/ra129.pdf, acesso em 07 nov. 2015.

BRITO, J. R. F.; PINTO, S. M.; BRITO, M. A. V. P. Boas práticas de produção de leite bovino na agricultura familiar. In: Recomendações básicas para aplicação das boas práticas agropecuárias e fabricação na agricultura familiar. Embrapa informação tecnológica. Brasília, DF. 2006. p.195-206.

CARNEIRO, M. J. Ruralidade: novas identidades em construção. Estudos Sociedade e Agricultura; out.1998, p. 53-75. Disponível em: http://r1.ufrri.br/esa/V2/ojs/index.php/esa/article/view/135/131, acesso em 28 jan. 2015.

CARVALHO, S. A. de; TOURRAND, J. F.; POCCARD-CHAPUIS, R. Atividade leiteira : Um desafio para a consolidação da agricultura familiar na região da Transamazônica, no Pará. Cadernos de Ciência e Tecnologia. V.29, n.1, jan/abr.2012.

CHAYANOV, A. La teoría de la economía campesina. $2^{\circ}$ edição. Ed. PYP, México, 1987, 198p.

FARAH, M. F. S. Disseminação de inovações e políticas públicas e espaço local. In: o\&s - v.15 - Abril/Junho, 2008.

FILHO, H. M. de S. et al. Condicionantes da adoção de inovações tecnológicas na agricultura. Cadernos de Ciência \& Tecnologia, Brasília, v. 28, n.1, p.223-255, jan/ab.2011.

http://ainfo.cnptia.embrapa.br/digital/bitstream/item/86647/1/condicionantes-daadocao.pdf, acesso em 16 jan. 2015. 
GEHLEN, I. Pesquisa, tecnologia e competitividade na agropecuária brasileira. Dossiê. Sociologias, Porto Alegre/RS, ano 3, $n^{\circ} 6$, jul/dez, 2001, p.70-93. Disponível em: http://www.scielo.br/pdf/soc/n6/a05n6.pdf, acesso em 17 jan. 2015.

Guia de boas práticas na pecuária de leite. Produção e saúde animal diretrizes. FAO e IDF. Roma, 2013.

HARVEY, M.; MCMEEKIN, A.; WARDE, A. Qualities of food. New York: Palgrave, 2004.

HÉBETTE, J. Cruzando a fronteira: $\mathbf{3 0}$ anos de estudo do campesinato na Amazônia (Vol. I). Belém: EDUFPA, 2004. 373 p.

HOSTIOU, N.; VEIGA, J. B. da; TOURRAND, J. F. Dinâmica e evolução de sistemas familiares de produção leiteira em Uruará, frente de colonização da Amazônia Brasileira. In: Revista de Economia e Sociologia Rural. Vol $44 n^{\circ} 2$. Brasília, abril/jun, 2006, p. 295-311. ISSN 0103-2003.

INSTITUTOBRASILEIRO DE GEOGRAFIA E ESTATÍSTICA. Produção da Pecuária Municipal 2014. Vol 42, Rio de Janeiro: IBGE, 2014, p. 1-39. Disponível em: http://www.ibge.gov.br/home/estatistica/economia/ppm/2014/ , acesso em 05 nov. 2015,

LAMARCHE, H. (coord.). Agricultura familiar:1. uma realidade multiforme. Campina, Unicamp, 1993.

MESQUITA, B. A. de. Demanda por alimentos e as consequências na Amazônia brasileira: "sucesso" do agronegócio e tragédia do desmatamento.

Observatóriogeograficoamericalatina.org.mx. Disponível em: http://www.observatoriogeograficoamericalatina.org.mx/egal12/Procesosambientales Impactoambiental/81.pdf, acesso em 16 jan. 2015.

MINISTÉRIO DA AGRICULTURA PECUÁRIA E ABASTECIMENTO. Instrução Normativa $n^{\circ} 16$. Brasilia, DF, 2015. Disponível em:

https://www.legisweb.com.br/legislacao/?id=286090, acesso em 30 out. 2015.

MILINSKI, C. C.; GUEDINE, P. S. M.; VENTURA, C. A. A. O Sistema Agroindustrial do leite no Brasil: uma análise sistêmica. In: Congresso Brasileiro de Sistemas, 4. 2008, Franca. Anais...Franca: Uni-FACEF, 2008. Disponível em: http://legacy.unifacef.com.br/quartocbs/artigos/C/C 151.pdf, acesso em 20 jan. 2015. 
NAVEGANTES-ALVES, L. et al. Transformações nas práticas de criação de bovinos mediante a evolução da fronteira agrária no sudeste do Pará. In: Cadernos de Ciências e Tecnologia. V.29, n.1, jan/abr, 2012, p.243-268.

RIBEIRO, L. P.; BRANT, F. L. C.; PINHEIRO, T. M. M. Desenvolvimento econômico rural, apoio à agricultura familiar política pública para a manutenção da vida e do trabalho no campo: Um relato de experiência no município de Santo Antônio do Monte/MG. Revista Cereus. V. 6, n.2, mai/ago, 2014. UnirG, Gurupi/TO, Brasil. ISSN: 2175-7275.

ROUGEMONT, J. A. Alimentos seguros - necessidade ou barreira comercial. Revista Perspectivas On line, v. 1, $n^{\circ} 2$, p. 62-70, 2007. Disponível em: http://www.conhecer.org.br/download/BOAS\%20PRATICAS\%20DE\%20FABRICACA O/Leitura\%203.pdf, acesso em 16 jan. 2015.

SANTINI, G. A.; PEDRA, D.F.B.N.; PIGATTO, G. Internacionalização do setor lácteo: a busca pela consolidação. In: Congresso Anual da Sociedade Brasileira de Economia Administração e Sociologia Rural. 2009.

Disponível em: http://www.sober.org.br/palestra/13/831.pdf, acesso em 28 jan. 2015.

SANTOS, M. Difusão de inovações ou estratégias de vendas. In: SANTOS, Milton. Economia Espacial - Críticas e alternativas. $2^{a}$ Ed. São Paulo: Edusp, 2011. Cap 2, p. 41-74.

WANDERLEY, M. N. B. Territorialidade e ruralidade no Nordeste - Por um pacto social pelo desenvolvimento rural. In: SABOURIN, E.; TEIXEIRA, O. A. (Ed. Téc.). Planejamento e desenvolvimento dos territories rurais - Conceitos, controvérsias e experiências. Brasilia: Embrapa informação tecnológica, 2002. Cap. 2, p. 39-52.

WANDERLEY, M. N. B.; Agricultura familiar e campesinato: rupturas e continuidade. Estudos Sociedade e Agricultura. Rio de janeiro, v. 21, p. 42 - 61, 2003.

\section{Artigo}

Recebido em 16 de Julho de 2015

Aceito em 12 de Fevereiro de 2016

R. Inter. Interdisc. INTERthesis, Florianópolis, v.13, n.1, p. 52-74 Jan-Abr. 2016 